\title{
Selection of direct drives for tool and workpiece rotation for gear- hobbing machines of new generation
}

\author{
Vladimir Novikov ${ }^{1, *}$, Alexey Isaev ${ }^{1}$, and Viktor Bushuev ${ }^{1}$ \\ ${ }^{1}$ Sub-department "Machine tools" of MSTU "STANKIN", 127055 Moscow, Russia
}

\begin{abstract}
Selection of direct drives for tool and workpiece rotation based on their computed torques for gear-hobbing machines of new generation is considered. Significant influence of torsional stiffness of electromechanical drive system, their tuning and peculiarities of operation in the continuous tracking mode on the drives' maximum torque is shown.
\end{abstract}

\section{Features of gear-hobbing machines of new generation}

Modern machine tools of new generation are built, as a rule, on the basis of mechatronic modules for realization of shape-generating motions, and the interrelated rotations of the tool and workpiece are implemented by means of direct drives mounted on the corresponding spindles. In this case, both design and operational advantages are achieved.

This paper deals with selection of the torque values of the drives for the rotation of cutting tool and workpiece in the new generation gear-milling machine 2200 mod. $5320 \mathrm{~F} 4$ with accuracy $\mathrm{P}$ class is considered. The machine tool is designed at MSTU "STANKIN" and manufactured by the machine-tool plant "SASTA" JSC (Sasovo, Ryazan region).

When creating new generation machine tools with main performance indicators depending on the electromechanical properties of drives, a number of completely new and serious problems arise, including the choice of the force-torque parameters of the drives.

Let us consider the main distinctive features of direct drives of gear-hobbing machines affecting the their torques:

1. The lack of intermediate gears in the short generating train of the machine allows to achieve the maximum possible mechanical torsional stiffness.

2. Dynamic characteristics of the drive depended on its tuning affect the stiffness (the ratio of torque variation to the angle of rotation variation) and the maximum component of the cutting torque per revolution of the hob.

3 . The drives are continuously working in the tracking mode, providing a constant gear ratio between the hob and the workpiece, so apart from the cutting torque, they consume the torque for acceleration (acceleration and braking) of the motors.

The experiments were carried out on a prototype model of the machine $\varnothing 200 \mathrm{~mm}$ mod. 5320F4 at the
MSTU "STANKIN". Steel workpieces of gear wheels with different number of teeth and modules $(\mathrm{m}=3 ; 4 ; 6)$ were machined with worm hobs. The gear hobbing was carried out mainly in one pass (at the full height of the tooth) with feed rate ranging from 1 to $4 \mathrm{~mm} / \mathrm{rev}$. During the work, measurement of torques at the table and the tool, the rotation speeds and spindle rotation angles (machine sensors), cyclic errors of the generating train were conducted.

\section{Study of the cutting torques during roughing}

Experimental investigations of cutting forces and torques during rough machining on traditional machines have shown that per single table revolution the torque changes approximately according to the sinusoidal law with frequencies equal to the number of cut teeth $Z$ and the $Z \cdot Z_{0}$ product, where $Z_{0}$ is the number of flutes in the worm hob $[1,2,3,4]$. The maximum torque on the worm hob is about 2 times higher than the average.

Figure 1 shows typical graphs of the torque on the drives when roughing the gear with the following parameters: $m=4 ; Z=36 ; \beta=0^{0}$, with the following cutting parameters: cutting depth $t=9 \mathrm{~mm}$; cutting speed $V_{\mathrm{HOB}}=24$ $\mathrm{m} / \mathrm{min}$; feed rate $S=3,6 \mathrm{~mm} / \mathrm{rev} . M_{\mathrm{MAX}}, M_{\mathrm{AVR}}, M_{\mathrm{CONST}}-$ maximum, average and constant torque on the drives; $M_{\mathrm{MAX}(\mathrm{AVR})}$ is the average of the maximum (peak) values of the torques per revolution of the hob (according to the number of flutes).

\footnotetext{
Corresponding author:9bobah@gmail.com
} 

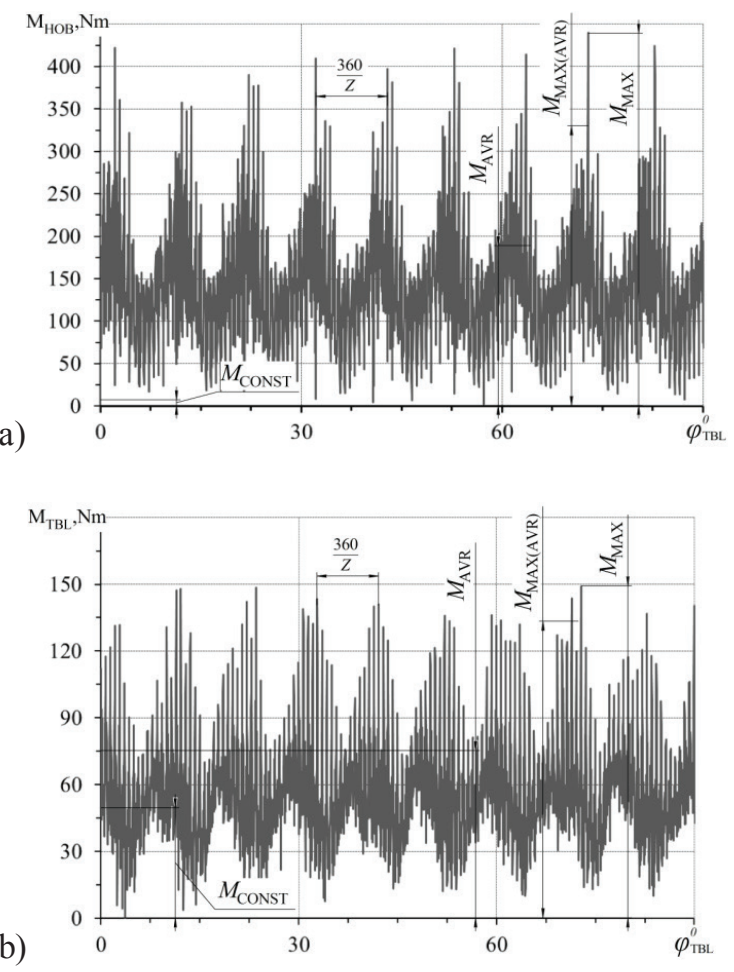

Fig.1 The graphs of the moments of the worm hob (a) and the table (b) when roughing the tooth wheel with the adjustment of the drives to the maximum passband for 0.5 revolutions of the table.

The torque has 18 peaks per 0.5 revolutions of the table, according to the number of gear teeth $(Z=36)$. At the maximum cross section of the removed chips, the maximum torque $M_{\mathrm{MAX}}$ appears. The torque at the hob is changing as at machines with mechanical generating train, except for the increased value of the maximum to average torque ratio. Important parameters when choosing drives of hobbing machines are: mean peak torques $M_{\mathrm{MAX}(\mathrm{AVR})}$ per revolution of the hob (according to the number of flutes) and the maximum torque $M_{\mathrm{MAX}}$.

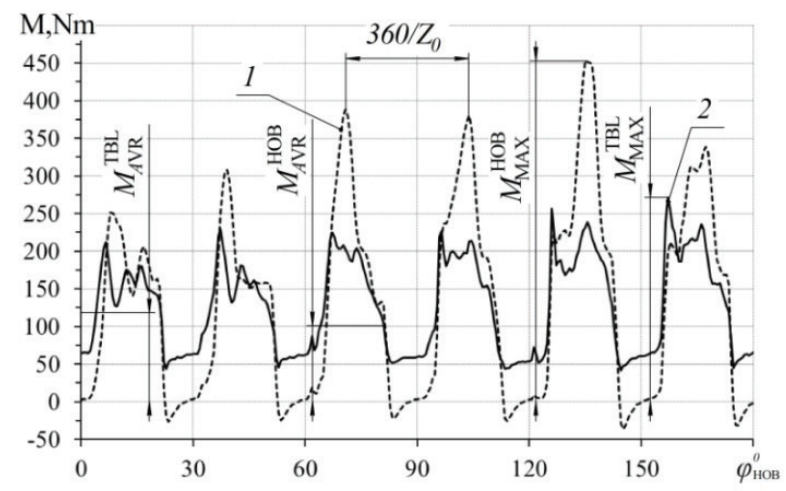

Fig.2 Torques of the hob (1) and the table (2) for rough cutting when rotating the hob at $180^{\circ}$

Figure 2 shows the torques of the $M_{\mathrm{HOB}}$ worm hob and the $M_{\text {TBL }}$ table when machining a steel helical wheel under cutting parameters close to the maximum achievable ones at this machine, namely: $m=6 ; \quad Z=29 ; \quad \beta=20^{\circ}$; $t=2,25 \cdot m=13,5 \mathrm{~mm} ; \quad V_{\mathrm{HOB}}=24 \mathrm{~m} / \mathrm{min} ; \quad S=1.5 \mathrm{~mm} / \mathrm{rev}$; $Z_{0}=12$. The graphs show 6 maximum peaks of torque at $180^{\circ}$ (according to the number of flutes).

The maximum torque at the hob $M_{\mathrm{MAX} \cdot \mathrm{HOB}}=455 \mathrm{Nm}$ has exceeded the average $M_{\mathrm{AVR} \text {. HOB }}=150 \mathrm{Nm} \sim 3$ times and limited the further increase of cutting parameters for the permissible torque on the engine $\left(M_{\mathrm{MAX}(\mathrm{NGN} . \mathrm{HOB})}=500 \mathrm{Nm}\right)$. The maximum torque at the table $M_{\text {MAX.TBL }}=270 \mathrm{Nm}$ has exceeded the average $M_{\mathrm{AVR} . \mathrm{TBL}}=160 \mathrm{Nm}$ in 1.7 times and does not limit the possibility of further increase in cutting parameters $\left(M_{\mathrm{MAX}(\mathrm{NGN} \cdot \mathrm{TBL})}=716 \mathrm{Nm}\right)$.

Table 1 shows the average experimental data on the analysis of torques on the drives, obtained from the roughing of steel workpieces with modules 3,4 and $6 \mathrm{~mm}$, with different cutting parameters.

Table 1. Average torques at the drives during roughing operations.

\begin{tabular}{|l|c|c|c|c|l|}
\hline & $\begin{array}{l}\mathrm{M}_{\text {MAX }}, \\
\text { Nm }\end{array}$ & $\begin{array}{l}\mathrm{M}_{\text {MAX(AVR) }}, \\
\text { Nm }\end{array}$ & $\begin{array}{l}\mathrm{M}_{\text {AVR }}, \\
\mathrm{Nm}\end{array}$ & $\begin{array}{l}\mathrm{K}_{\mathrm{M}}, \\
\mathrm{Nm}\end{array}$ & $\begin{array}{l}\mathrm{K}_{\text {AVR }}, \\
\mathrm{Nm}\end{array}$ \\
\hline hob & 300 & 200 & 100 & 3 & 2 \\
\hline table & 200 & 175 & 120 & 1,7 & 1,5 \\
\hline
\end{tabular}

Where $K_{\mathrm{M}}=M_{\mathrm{MAX}} / M_{\mathrm{AVR}}$;

$$
K_{\mathrm{AVR}}=M_{\mathrm{MAX}(\mathrm{AVR})} / M_{\mathrm{AVR}}
$$

The maximum torque at the hob $\left(M_{\mathrm{MAX}}\right)$ exceeds the average torque by approximately 3 times ( 2.8 to 3.2 times depending on cutting parametes). The average values of peak torques per revolution of the hob (M $\left.M_{\mathrm{MAX}(\mathrm{AVR})}\right)$ exceed the average torque at the hob by 2 times, and by 1.5 times at the workpiece.

The results obtained for increasing the maximum torque by 3 times relative to the nominal differ from the results obtained on machines with traditional relatively non-rigid kinematics, where the maximum torque exceeds the average by approximately 2 times $[1,2,3,4]$.

Therefore, to test the suggested hypothesis of increasing the maximum torque $\left(M_{\mathrm{MAX}}\right)$ due to an increase in the torsional rigidity of the generating train, experiments were conducted with different tuning of the drives which affects the change in the "electrical" component of the torsional stiffness. The following values of the bandwidth of the drives for speed were achieved, depending on the settings: for the hob $f=55-410 \mathrm{~Hz}$; for the table $f=16-175 \mathrm{~Hz}$. The work of the drives was studied under conditionally called "good" tuning $\left(f_{\mathrm{HOB}}=410 \Gamma ц\right.$; $\left.f_{\mathrm{TBL}}=175 \Gamma ц\right)$ and "bad" tuning $\left(f_{\mathrm{HOB}}=55 \mathrm{~Hz} ; f_{\mathrm{TBL}}=\right.$ $16 \mathrm{~Hz})$.

\section{Influence of the drive control settings on the cutting torque}

Figure 3 shows the graphs of the torques on the drives with the "bad" setting (at the cutting parameters shown in Fig. 1), within 0.25 turn of the hob, where 1, 2 and 3 are the torques caused by the motor acceleration, the total torque (dotted line) and the cutting torque, 
Table 2. Effect of the quality of the drive settings on their moments.

\begin{tabular}{|c|c|c|c|c|c|c|c|c|c|}
\hline \multicolumn{2}{|c|}{ Tuning quality } & \multirow{2}{*}{\begin{tabular}{|c|} 
Bandwidth $\mathrm{f}, \mathrm{Hz}$ \\
410 \\
\end{tabular}} & \multirow{2}{*}{\begin{tabular}{|c|}
$\begin{array}{l}\mathrm{M}_{\mathrm{MAX}} \\
\mathrm{Nm}\end{array}$ \\
440 \\
\end{tabular}} & \multirow{2}{*}{$\begin{array}{c}\text { Mmax,Nm } \\
250 \\
\end{array}$} & \multirow{2}{*}{\begin{tabular}{|c}
$\mathrm{M}_{\mathrm{ABR}}, \mathrm{Nm}$ \\
175 \\
\end{tabular}} & \multirow{2}{*}{\begin{tabular}{|c|} 
MCONST, $\mathrm{Nm}$ \\
50 \\
\end{tabular}} & \multirow{2}{*}{\begin{tabular}{|c|}
$\Delta \mathrm{M}_{(\mathrm{MAX})}, \mathrm{Nm}$ \\
37
\end{tabular}} & \multirow{2}{*}{\begin{tabular}{|c|}
$\mathrm{M}_{\mathrm{MAX}} / \mathrm{M}_{\mathrm{AVR}}$ \\
2,51 \\
\end{tabular}} & \multirow{2}{*}{$\begin{array}{c}\mathrm{M}_{\text {MAX }} / \mathrm{M}_{\text {MAX(AVR) }} \\
1,76 \\
\end{array}$} \\
\hline "good" & hob & & & & & & & & \\
\hline 'good" & table & 175 & 170 & 120 & 75 & 25 & 16 & 2,26 & 1,41 \\
\hline \multirow{2}{*}{$\begin{array}{l}\text { "bad" } \\
\& \\
\text { "bad" }\end{array}$} & hob & 55 & 335 & 245 & 150 & 30 & 18 & 2,2 & 1,37 \\
\hline & table & 16 & 135 & 105 & 70 & 18 & 10 & 1,93 & 1,29 \\
\hline
\end{tabular}

respectively. Since the HSS worm hob used in the experiment has 14 flutes $\left(Z_{0}=14\right)$, the graphs show 4 maximum peak torques at the angle of 90 degree. In addition to the cutting torque, the torques $M \varepsilon$ caused by the acceleration of the engines are shown, which have about 10 peaks between the two cuts of the worm hob.

a)

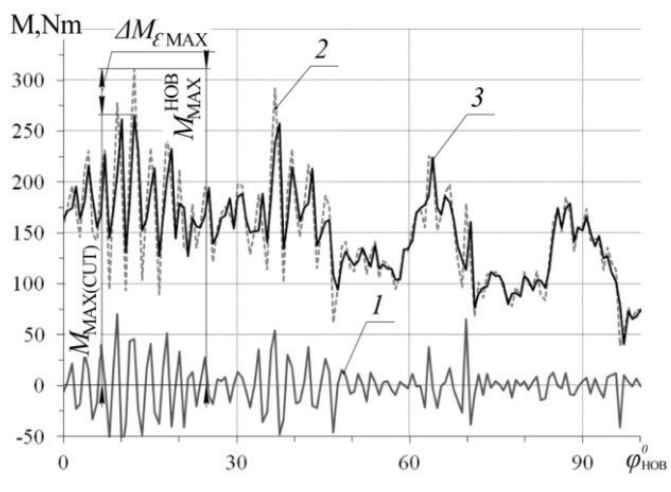

b)

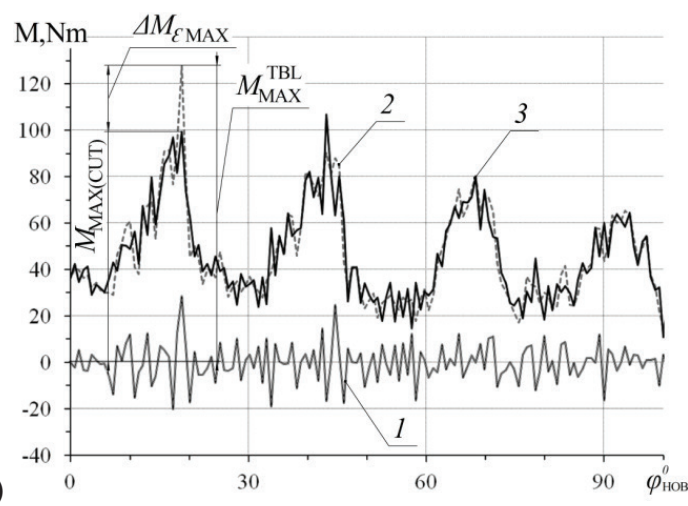

Fig.3 Torques at the hob (a) and the worktable (b) for roughing the wheel, taking into account the cutting, acceleration and friction moments.

The total torques of the drive is total (for the example of the maximum torque):

$M_{\mathrm{MAX}}=M_{\mathrm{MAX}(\mathrm{CUT})}+\Delta M_{\varepsilon(\mathrm{MAX})}$, where

$M_{\mathrm{MAX}(\mathrm{CUT})}$ is the maximum cutting torque, which includes the constant component of the $M_{\text {CONST }}$ torque, which depends on the friction in the spindle bearings;

$\Delta M_{\varepsilon(\operatorname{MAX})}$ is the acceleration moment;

Acceleration moment (Fig. 1) can both increase and decrease the maximum drive torque during the cutting process.

The influence of the quality of the adjustment of the drives on their moments and torques during the machining of the wheels in Fig. 3 is illustrated by the data in Table 2.
It follows from Table 2, that all the moments and torques described in this table have increased with the improvement of the quality of the settings and the bandwidth of the drives. The maximum torque $M_{\mathrm{MAX}}$ at the hob and the table has increased $\sim$ by $25-30 \%$ with improvement of the drive tuning.

\section{Study of drives rigidity}

Let us define the "electric" torsional stiffness of the drives $C_{\mathrm{E}}=\Delta M / \Delta \varphi$ equal to the ratio of the torque variation $\Delta M$ to the drive torsional deformation variation $\Delta \varphi$ in the area of one cut of the hob (see Fig. 4), i.e. at its turn on an angle $\varphi=360 / Z_{0}$ (similar to the rigidity in the mechanical system).

Fig. 4 shows, as an example, the graphs of the torque variation $\Delta M$ of the worm hob drive and the corresponding variation of the worm hob rotation angle $\Delta \varphi$ and the table for their "bad" adjustment and for the cutting parameters shown in Fig. 1.

a)

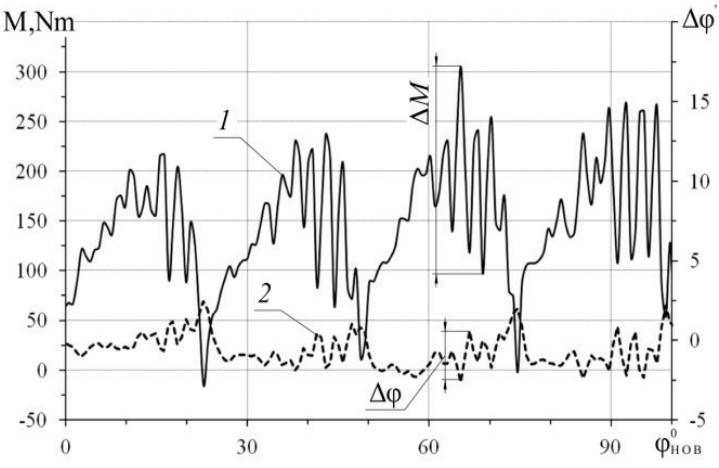

b)

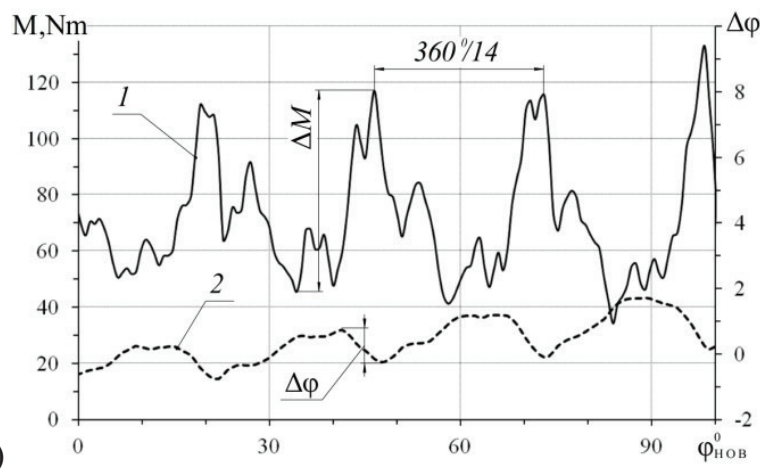

Fig.4 Torques and moments (1) and errors of angles of rotation (2) of hob (a) and table (b) with "bad" tuning of drives

Table 3 shows the average values of the stiffness of the drives $C_{\mathrm{TS}}$ and their "electrical" $C_{\mathrm{E}}$ and "mechanical" 
$C_{\mathrm{M}}$ components for the rough machining of the same workpiece with different drive tuning.

Table 3. Rigidity of drives with different settings.

\begin{tabular}{|l|l|l|l|l|}
\hline drive & tuning quality & $\begin{array}{l}C_{\mathrm{E}}, \\
\mathrm{Nm} / \mathrm{rad}\end{array}$ & $\begin{array}{l}C_{\mathrm{M}}, \\
\mathrm{Nm} / \mathrm{rad}\end{array}$ & $\begin{array}{l}C_{\mathrm{TS}}, \\
\mathrm{Nm} / \mathrm{rad}\end{array}$ \\
\hline hob & bad & 144460 & 75670 & 49660 \\
\hline table & bad & 151340 & 670700 & 123480 \\
\hline hob & good & 189170 & 75670 & 54050 \\
\hline table & good & 213250 & 670700 & 161800 \\
\hline
\end{tabular}

"Electrical" stiffness was determined by the readings of the angular spindle position sensor. "Mechanical" stiffness was computed at the sections of the kinematic chains from the cutting zone to the angular position sensor. Tangential contact deformation of the joints of the pedestal with the table and the workpiece with the worktable were also taken into account in addition to the rigidity of the spindles, cotters and keys.

Table 3 has shown that the rigidity of the drives $C_{\mathrm{TS}}$ depends on their adjustment and it is increasing from "bad" tuning to "good" one by approximately 9 and 30\% for the hob and table, respectively, as the maximum $M_{\mathrm{MAX}}$ moments on drives 30 and $26 \%$ increase (See table 2). The "electric" stiffness has exceeded the "mechanical" rigidity by about 2.5 times at the hob but it is 3 times lower than "mechanical" stiffness at the table. During the calculation, contact deformations of the gears and keyed joints, as well as torsional deformations of the shafts were taken into account.

Thus, the main reason for maximum torque increase is a significant increase of electromechanical stiffness of drives of the generating train in machines with direct drives, in comparison with traditional machines. The aggregated calculation of torsional stiffness of the kinematic chain of the generating train of a traditional machine of the similar size has shown that the unit stiffness of hob is approximately by an order of magnitude less than the drive stiffness of the new generation machine.

An important feature the new generation machines' drives is their continuous operation in the tracking mode, which makes it necessary to take into account the acceleration and braking moments of the engine.

Those moments were determined using the formula $M_{\varepsilon}=I \cdot \mathcal{E}$, where $I$ is the moment of inertia of the rotating masses, and $\varepsilon$ is acceleration computed by differentiating the speed on the worm hob and the table.

In Fig. 5, the graphs of moments for roughing the gear are given as an example; $m=6 ; Z=50 ; \beta=16^{0} ; t=12 \mathrm{~mm}$; $S=1 \mathrm{~mm} / \mathrm{rev} ; Z_{0}=12$, where: $1,2,3$ - acceleration moment of the engine, total torque and moment from cutting (dotted line), respectively.

Thus, we have obtained the following specifications: -for the hob:

$I_{\mathrm{HOB}}=0,2 \mathrm{~kg} \cdot \mathrm{m}^{2} ; \varepsilon_{\mathrm{MAX}}=650 \mathrm{rad} / \mathrm{s}^{2} ; \varepsilon_{\mathrm{AVR}}=175 \mathrm{rad} / \mathrm{s}^{2} ;$ -for the table:

$I_{\mathrm{TBL}}=2,4 \mathrm{~kg} \cdot \mathrm{m}^{2} ; \varepsilon_{\mathrm{MAX}}=40 \mathrm{rad} / \mathrm{s}^{2} ; \varepsilon_{\mathrm{AVR}}=24 \mathrm{rad} / \mathrm{s}^{2} ;$

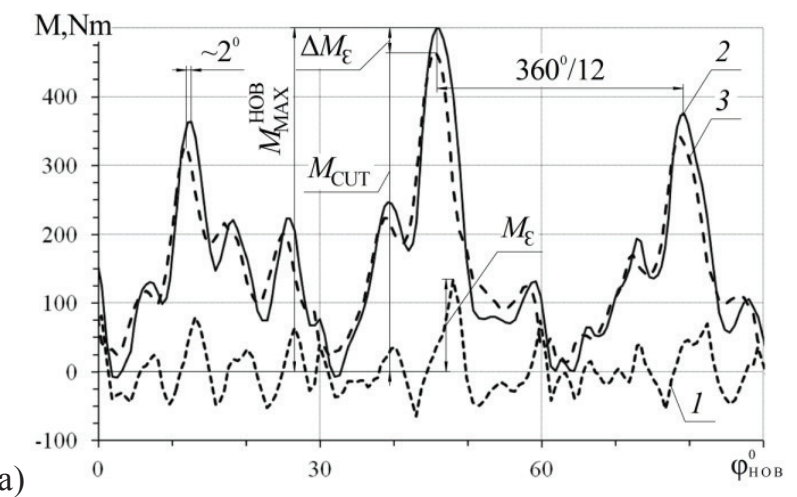

b)

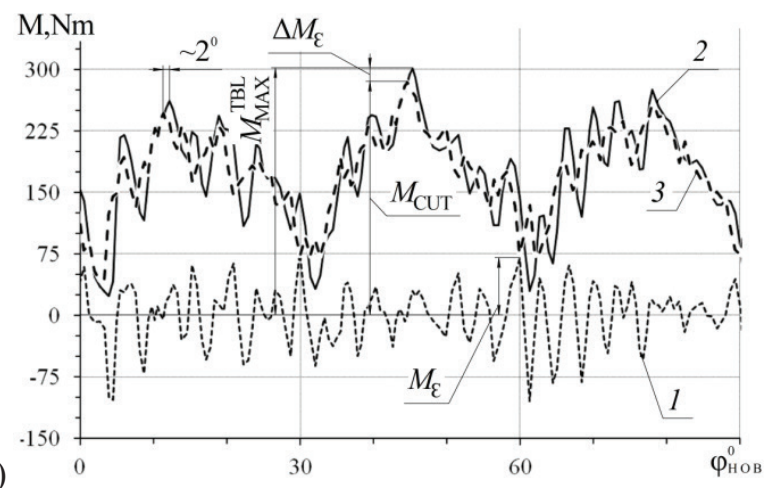

Fig.5 Torques at the hob (a) and worktable (b) when roughing the wheel

The maximum accelerating moment $M_{\varepsilon}$ coincides in phase (with a small lag of $\sim 2^{0}$ ) with the maximum cutting torque $M_{\text {CUT }}$ at the worm hob. This is the case for all peak torques for the turn of the hob, since it is the cutting torque that causes the speed to change. In the cases considered (when machining wheels with $\mathrm{m}=3 ; 4 ; 6$ ), the motor torque exceeds the cutting torque peaks: for the hob $-\Delta M_{\varepsilon}$ $=7 \div 10 \%$; For the table $-\Delta M_{\varepsilon}=8 \div 26 \%$.

The most strongly the accelerating moments affect the general torques of drives during finishing, since in some cases they become comparable with the cutting torques.

Analysis of the influence of the cutting process, under different cutting parameters and workpiece parameters, on acceleration torque $M_{\varepsilon}$, made it possible to establish accelerations for roughing and finishing operations:

The average value of the acceleration peaks (in terms of the number of flutes $Z_{0}$ ) was: on the hob - $\varepsilon_{\mathrm{AVR}(\mathrm{HOB})}=$ $160 \mathrm{Rad} / \mathrm{s}^{2}$ (varied from 70 to $400 \mathrm{Rad} / \mathrm{s}^{2}$ ); on the table $\varepsilon_{\mathrm{AVR}(\mathrm{TBL})}=17 \mathrm{Rad} / \mathrm{s}^{2}\left(\right.$ varied from 5 to $\left.40 \mathrm{Rad} / \mathrm{s}^{2}\right)$;

The maximum values are $\varepsilon_{\mathrm{MAX}(\mathrm{HOB})}=345 \mathrm{Rad} / \mathrm{s}^{2}$ (varied from 180 to $650 \mathrm{Rad} / \mathrm{s}^{2}$ ); $\varepsilon_{\text {MAX(TBL) }}=27 \mathrm{Rad} / \mathrm{s}^{2}$ (varied from 8 to $50 \mathrm{Rad} / \mathrm{s}^{2}$ );

At finishing operations, the acceleration is less than about 3 times that for roughing operations.

The conducted experiments showed that accelerations at the drives of the hob and at the table practically do not influence the average torque of the drives, but increase its maximum component $M_{\mathrm{MAX}}$ with coefficients $K_{\varepsilon(\mathrm{HOB})} \sim$ 1,1 for the hob and $K_{\varepsilon(\mathrm{TBL})} \sim 1,15$ for the table. 


\section{Algorithm for selecting torques of the main motions motors of new generation gear hobbing machines}

Based on the results of the research, the following algorithm is proposed for selecting the torques of drives for rotating hob and workpiece:

1. Taking into account the characteristic parameters of the tools and machined wheels, using the recommended (close to maximal) cutting parameters (module, feed, depth, etc.), according to existing formulas from the literature determine the required average torque at the hob. For increased productivity, reference values of feed rate can be increased by at least 1,5 times (if these are not limited by the cutting process itself), since in the new generation machines the cutting parameters are limited as a rule by the torques of the drives.

The average torque of the worktable is determined by:

$$
M_{\mathrm{AVR}} \geq\left(F_{\mathrm{Z}} \cdot \sin \beta+F_{\mathrm{X}} \cdot \cos \beta\right) \cdot d_{\mathrm{WKPC}} / 2+M_{\mathrm{FR}},
$$

Where $F_{Z}$ is the average value of the tangential component of the cutting force;

$F_{\mathrm{X}}$ is a axial (along the axis of the hob) component of the cutting force (in the first approximation can be ignored);

$\beta$ is the maximum angle of inclination of the tooth;

$d_{\text {WKPC }}$ is the maximum diameter of the workpiece;

$M_{\mathrm{FR}}$ is the moment of friction in the table supports;

2. According to the calculated average torque, the $M_{\mathrm{AVR}}$ is determined:

The maximum torque at the engine:

$$
M_{\mathrm{MAX}}=M_{\mathrm{AVR}} \cdot K_{\mathrm{M}} \cdot K_{\varepsilon}
$$

The moment limiting the mode of operation $\mathrm{M}_{\mathrm{S} 6(40 \%)}$ :

$$
M_{\mathrm{MAX}(\mathrm{AVR})}=M_{\mathrm{AVR}} \cdot K_{\mathrm{AVR}} \cdot K_{\varepsilon}
$$

For hob:

For the table:

$$
K_{\mathrm{M}(\mathrm{HOB})}=3 ; K_{\mathrm{AVR}(\mathrm{HOB})}=2 ; K_{\varepsilon(\mathrm{HOB})}=1,1 ;
$$

$$
K_{\mathrm{M}(\mathrm{TBL})}=1,7 ; K_{\mathrm{AVR}(\mathrm{TBL})}=1,5 ; K_{\varepsilon(\mathrm{TBL})}=1,15 \text {; }
$$

3 . The computed values of the torques are then compared with drive specifications from catalogues, taking into account that:

$$
\begin{gathered}
M_{\mathrm{RT}} \geq M_{\mathrm{AVR}} ; \\
M_{\mathrm{NGN} . \mathrm{S} 6(40 \%)} \geq M_{\mathrm{MAX}(\mathrm{AVR})} \\
M_{\mathrm{MAX}(\mathrm{NGN})}>M_{\mathrm{MAX}} ;
\end{gathered}
$$

-it is recommended to select the drive motors on the average calculated cutting torque, determined using the known methods. The maximum permitted motor torque shall exceed the computed average torque by at least 3 times at the hob and 1.7 times at the workpiece.

-Moments in the drives arising from accelerations during their operation in a continuous tracking mode mainly affect the work at finishing operations.

This work was financially supported by the Ministry of Education and Science of Russian Federation in the framework of the state task in the field of scientific activity of MSTU «STANKIN» № 9.1372.2017/4.6.

\section{References}

1. Ya.I. Adam, G.G. Ovumyan, Spravochnik zuboreza[Gear cutter guide] (Moscow, Mashinostroenie, 1983)

2. V.V. Bushuev, S.P. Nalyotov, Tyazhelye zuboobrabatyvayushchie stanki.[Heavy gearhobbing machines] 2nd revised and enlarged edition (Moscow: Mashinostroenie, 1986)

3. V.N. Bashkirov, A.A. Serov, Opredelenie secheniya sreza pri zubofrezerovanii cilindricheskih kolyos chervyachnoj frezoj.[Determination of the cross section of cut in the gear hobbing of cylindrical wheels with a hob cutter] (Stanki i instrument, 1984)

4. Ali M. Abood. Dynamic Analysis Of The Cutting Forces In Gear Hobbing (University of Newcastle, UK., 2002)

5. Vl.Vas. Bushuev., Vik.Val. Bushuev, V.A. Novikov. Kinematicheskaya tochnost' zubofrezernyh stankov novogo pokoleniya[Kinematic accuracy of the new generation gear hobbing machines], Vestnik MGTU "STANKIN" №3(38) (2016).

\section{Conclusions}

-The maximum moments and torques arising in the direct drives of the hob and workpiece in the gearhobbing machines of new generation depend on the parameters of the cutting process, as well as on the torsional stiffness of the drives and the quality of their tuning, and exceed the maximum moments and torques of machines with mechanical generating train by approximately 1.5 times. 